\title{
EDITORIAL
}

\section{Revista de Nutrição inaugura seção temática}

A Revista de Nutrição é regularmente editada desde 1988 (originalmente como Revista de Nutrição da PUCCAMP), numa trajetória de permanente aperfeiçoamento de seu projeto editorial. A partir de 2005, sua periodicidade passou a ser bimestral, o que promove um avanço no tocante ao número de contribuições, alcançando, no volume 19, a publicação de 71 artigos.

Em direção à maior qualificação e ao atendimento das demandas dos pesquisadores, inaugura, com este número, a Seção Temática, que congrega reflexões sobre o I Fórum de Coordenadores de Pós-graduação em Nutrição, ocorrido em junho de 2006, na cidade de Salvador (Bahia), expressas nos três artigos aqui disponibilizados.

No primeiro deles, Panorama atual dos programas de pós-graduação em nutrição no Brasil, Gilberto Kac, Eliane Fialho e Sandra Maria Chaves dos Santos traçam um perfil dos programas, partindo do exame dos relatórios anuais da Coordenação de Aperfeiçoamento de Pessoal de Nível Superior (CAPES). Identificam o número ainda pequeno de programas de Nutrição, boa parte dos quais recentemente instalados; apontam para a necessidade de fomentar programas de doutorado, de aprimorar a produção intelectual e de apoiar os periódicos científicos específicos da Nutrição.

No segundo texto, Reflexões do I Fórum de Coordenadores de Programas de Pós-graduação em Nutrição no Brasil (Gilberto Kac, Eliane Fialho, Sandra Maria Chaves dos Santos e Ana Marlucia Oliveira Assis), os autores sistematizam as discussões, tendo como base os depoimentos dos participantes. Das formulações produzidas, atentam para a proposta de construção de agendas temáticas relevantes ao amadurecimento da pesquisa em nutrição; e mencionam o número limitado de periódicos nacionais especializados e a íntima relação entre o incremento da produção científica e o aprimoramento da pós-graduação. O empenho no desenvolvimento de estratégias para a melhor classificação dos periódicos científicos, diretamente identificados com a área de alimentação e nutrição, é outra idéia expressa entre as conclusões do referido texto. Por fim, os autores apontam a urgência de organização política da área, via fundação de uma associação de pós-graduação, capaz de veicular os interesses coletivos dos pesquisadores em alimentação e nutrição.

No terceiro artigo, Fator de impacto e pós-graduação stricto sensu em alimentos, nutrição e ciência e tecnologia de alimentos, Alceu Afonso Jordão, Rosa Wanda Diez Garcia e Júlio Sérgio Marchini discutem a produção científica, à luz dos indicadores de impacto dos periódicos e das agências de fomento. Os autores reconhecem o papel das medidas de produção na avaliação da pós-graduação, ao mesmo tempo em que problematizam sobre a necessidade de considerar as especificidades de cada área do conhecimento, em defesa de maior eqüidade no julgamento dos programas.

Chamam atenção, entre as questões levantadas nos três artigos, a premência em mobilizar a comunidade científica, o compromisso com a produção de espaços para o debate, em eventos específicos 
da nossa área, e o propósito de fortalecer os periódicos científicos especializados, como requisitos para a qualificação dos programas de pós-graduação em nutrição no Brasil.

A Revista de Nutrição sente-se honrada em veicular a presente edição, como contribuição a esse processo. Uma vez que, há algum tempo, é consultada sobre a possibilidade de publicação de números especiais, com a socialização desses resultados, destaca a feliz convergência de interesses que conduziu à proposição desta Seção Temática, e que enseja a inserção mais orgânica deste periódico no meio acadêmico e profissional.

Maria Angélica Tavares de Medeiros

Editora 